\title{
SURGICAL MANAGEMENT OF SPINAL CORD CYSTS
}

\author{
By ROBERT E. EDgar, M.D. \\ Craig Rehabilitation Center, Swedish Neurological Center, Denver, Colorado, U.S.A.
}

THE first documented operative approach to a cyst of the spinal cord was a myelotomy performed in 1892 by Abbe and Coley (I892). Subsequently, Elsberg (I9I6) and Poussepp (I926) performed myelotomy upon spinal cord cysts so that this procedure was initially referred to as the 'Elsberg-Poussepp operation'. In I94I ten cases were treated in this manner by Worster-Drought et al. Gardner et al. (1957) and Gardner and Angel (1959) described the innovative approach of suboccipital craniectomy with obliteration of the foramen caecum in congenital communicating syringomyelia. In 1966, Love and Olafson presented 44 cases of syringomyelia treated by different procedures such as posterior decompressive laminectomy, needle aspiration, polyethylene tube syringostomy, silk suture syringostomy, and tantalum wire syringostomy. In 1967 Conway suggested the use of low-pressure ventriculojugular shunt in cases of combined congenital hydrocephalus and syringomyelia. In 1973 Barnet et al. reported eight cases of post-traumatic cystic myelopathy treated by cordectomy and/or silastic tube syringostomy. This presentation describes a new procedure, myelocyst-peritoneal shunt, developed to treat both congenital and acquired cysts of the spinal cord.

\section{Surgical Method}

General anesthesia is used in all cases. The patient is positioned prone and a midline spinal skin incision is made. In this series, this has been cervical or thoracic, depending upon cyst location. A one or occasionally two laminal arch laminectomy is performed at a virginal site away from known areas of arachnoiditis, block, or original trauma. The dura is opened a distance of one inch and the midline of the spinal cord is identified. A 25-gauge needle is inserted into the midline raphe in an avascular area and hence into the cyst. This opening is enlarged by an I8-gauge and a I 5-gauge needle sufficient to produce a hole through which the silastic tube will pass. No incisional myelotomy is performed. A rightangled probe is then inserted into this opening and the posterior aspect of the spinal cord elevated slightly. The silastic tube is inserted into the cyst for a distance of four to seven centimetres. The cyst tube has radio-opaque markings on its tip and at several centimetre distances. Multiple openings in the end and sides of the cyst tube should be present but none should be near the entrance of the tube into the spinal cord. This tube is brought out through the subarachnoid space into the epidural space where a right-angle hard connector is tied to it by silk sutures. In the last case, for research purposes, a second shunt tube was left in the subarachnoid space with its tip at the exit point of the first cyst tube. It was then brought out through a separate opening in the dura. The dura was closed with interrupted No. 4 silk suture and dural purse string sutures were placed around the shunt tubes at their exit points. A right-angle hard connector was attached to the subarachnoid shunt tube.

$$
\mathrm{I} 4 / \mathrm{I} \longrightarrow \mathrm{C}
$$


A subcutaneous pouch is then made on the right above the fascia and below the subcutaneous fat. Two long Raimondi silastic tubes are anchored to the two right-angle connectors and a silver clip is placed on the subarachnoid shunt tube to identify it at a later stage in the operation. This excess tubing is then placed into the subuctaneous pouch which, at this point, is located over the top of the trapezius muscle on the right side. The incision is closed and dressed in the usual manner and the patient is repositioned in the supine posture. The patient is reprepped and draped and a one-inch incision is made over the right trapezius muscle and the two previously described tubes are identified and pulled into this opening. A four-inch right upper quadrant vertical paramedian abdominal incision is performed and a one-inch peritoneal incision made. Approximately I5 centimetres of the peritoneal tube is inserted into the right upper peritoneal cavity over the dome of the liver away from omentum. As previously mentioned, all subcutaneous and peritoneal tubes are of the Raimondi type with imbedded coiled wire to prevent obstruction by pressure or kinking.

A subcutaneous tunnel is then made from the peritoneal cavity upward to the midsternum, where a two-inch incision is made in the mid-sternal region. A subcutaneous tunnel is made from the sternal incision to the trapezius incision and the two tubes are brought through this tunnel into the sternal area. Excess tubing is cut off and care is taken to be sure that the subarachnoid tube, previously identified by a silver clip, is separated from the cyst shunt tube. The subarachnoid tube is anchored by a connector to a blind-ended reservoir. The cyst tube is then connected by a hard connector to the Heyer-Schulte multi-purpose shunt valve. This valve is then connected to the peritoneal tube. The blindended reservoir and the multi-purpose valve are both fixed to the episternal subcutaneous tissue. Care should be taken to place these valves right in the midline directly under the skin with minimal intervening subcutaneous tissue so they are easily visible and palpable postoperatively. The sternal placement is important to ensure a solid flat surface needed during postoperative manual digital manipulation. Function of the system is checked and the wounds are closed in the usual manner.

\section{Case Reports}

Case No. I. I. D., 49-year-old female. Auto accident on 9 April 1966 . Immediate C5-6 sensory motor quadraplegia with $\mathrm{C}_{5}-6$ fracture subluxation. Immediate posterior cervical laminectomy and cranial tongs. Improvement with sensory drop of 2-3 segments. Three years later in $1969, \mathrm{~T}_{3}$ fracture noted and thoracic myelogram showed complete block at T3. Thoracic laminectomy in 1969 revealed 'scar tissue'. One and one half years' progressive loss of motor strength in uppers especially on the left with loss of pain and temperature sensation in uppers, left greater than right. Occipitalcervical pain and hyperhydrosis. Cervical myelogram on 26 July 1974 showed block from $\mathrm{C}_{5}-6$ to $\mathrm{T}_{4}-5$ with widening cervical cord from $\mathrm{C}_{2}$ to $\mathrm{C} 6$. Intramedullary myelography on 26 July 1974 showed cord cyst $\mathrm{C}_{2}$ to $\mathrm{T}_{4}$. Cervical laminectomy on $3 \mathrm{I}$ July I974 with cervical spinal cyst-subarachnoid silastic shunt tube. Rapid progressive improvement in pain and temperature sensation, hyperhydrosis and occipital pain with increased strength in uppers.

Case No. 2. H. Z., 23-year-old male. C7-TI missle injury on 25 June 1972. Posterior cervical laminectomy on 26 July 1972. Spinal cerebral spinal fluid fistula with meningitis. Complete sensory-motor quadraplegic C 7 . Five to six months' progressive motor deterioration both uppers, left more than right. Two months' progressive loss 
of pain and temperature sensation in left arm. Neurologic-thermanesthesia and hypalgesia up to $\mathrm{C}_{2}$ on left with increased motor deficit both arms. Previous myelogram on 2I July 1972 showed complete block TI. Intramedullary myelography on 21 August I972 showed intramedullary cyst extending from $\mathrm{CI}_{\mathrm{I}-2}$ to $\mathrm{T}_{\mathrm{I}-2}$. Cervical laminectomy on 23 August 1974 and superior-inferior silastic cyst-subarachnoids shunts. Immediate and continued progressive improvement in sensory-motor function upper extremities.

Case No. 3. R. B., 29-year-old male. Automobile accident in 1963 with C5-6 partial quadraparesis. Ambulatory with one short leg brace. Progressive quadraparesis and in 1970 at Washington University, St. Lousi, Missouri, an exploratory cervical laminectomy was carried out. Patient was much worse following this. In I973 a cervical myelogram showed a block at C5-6 and in September 1973 at Washington University a second cervical laminectomy was done and a cyst was found. A myelotomy was done. Patient was almost complete $\mathrm{C}_{5}-6$ quadraplegic following this. He failed to improve and developed loss of pain and temperature sensation and progressive weakness of arms and hand so that he could not transfer. Neurological examination revealed spastic quadraplegia $\mathrm{C}_{5}-6$ complete with hemianesthesia and hypalgesia to $\mathrm{C}_{2}$ on the right and $\mathrm{C}_{3}$ on the left with marked atrophy and weakness of hand intrinsics. There was bilateral trigeminal hypalgesia. On 25 September 1974 intramedullary myelography showed spinal cord cyst extending from $\mathrm{CI}_{\mathrm{I}}$ to $\mathrm{L}_{\mathrm{I}}$. On 9 October 1974 a myelocyst peritoneal shunt was performed. Patient had no progression of neurologic deficit and dropped sensory level to $\mathrm{C}_{5}$ bilaterally. He increased strength in uppers so he could transfer. On I6 March I975 due to leakage of shunt tube a new shunt was installed. Patient has maintained improvement.

Case No. 4. C. M., 4I-year-old female university English teacher. Diagnosis of congenital syringomyelia. Symptoms started age 6 years. Slowly progressive quadraparesis with three episodes of acute neurologic symptoms suggestive of Gower's syringal hemorrhage. Patient had numerous neurological and neurosurgical consultations. Myelogram showed cervical block. No treatment was recommended. Neurologic examination revealed marked thoracic kyphoscoliosis with quadraparesis of marked degree with $\mathrm{C}_{3}$ bilateral pain-temperature level. Subjective bilateral trigeminal hypalgesia. On 24 October I974 intramedullary myelography revealed a large cyst extending from CI to T3. Computer axial tomography did not show hydrocephalus. On 29 November I974 a myelocyst-peritoneal shunt was performed. The patient has cessation of neurological deterioration and has shown improvement in wrist extensors with decrease in pain-temperature level. The shunt is functioning well.

Case No. 5. D. L., I9-year-old male. $\mathrm{C}_{4}-5$ fracture subluxation due to horse injury on 20 August 1974. Initially complete quadraplegia C5. Anterior C5-6 discectomy and fusion on 25 August 1974. On 13 December 1974 progressive weakness noted right arm. Neurologic status showed increased right arm weakness and thermanalgesia and hypalgesia to $\mathrm{C}_{4}$ on the left. Cervical myelogram on 16 December 1974 showed essentially complete block at C5-6. On I9 December 1974 intramedullary myelography showed a four-inch cervical cord cyst extending from approximately $\mathrm{C}_{7}$ to $\mathrm{C}_{2}$. On 19 December 1974 cervical myelocyst-peritoneal shunt was performed. No postoperative complications. Cessation of progression with lowering of sensory level on the left and improvement of wrist flexors.

Case No. 6. M. B., 30-year-old female whose illness dates to age 4 years when she developed a weakness in her left leg. Since that time she has had a progressive quadraparesis. A congenitally small cervical canal with spondylosis was found at the University of Kansas. Syringomyelia was considered. On I February I97I she underwent a C5-6 posterior cervical laminectomy and on 8 April I97I a thoracic fusion with Harrington rods for scoliosis. Postoperatively she was quadraplegic and underwent on 12/7I an anterior cervical fusion. She improved after this to a quadraparetic state but since 1972 has had slow progression neurologically. Neurologic examination revealed motor 
quadraparesis of variable degree with 40 per cent strength in proximal left leg, normal right leg and weakness uppers with intrinsic atrophy and areflexia, left arm worse than right. Sensory thermanesthesia and hypalgesia up to C6 bilaterally with patchy preservation posterior columns distally. On I 2 February 1975 intramedullary myelography showed a cervical cyst centred at $\mathrm{C}_{7}$. Computer axial tomography was normal. On I2 February 1975 a myelocyst peritoneal shunt was performed. Postoperative course was uneventful until patient developed a skin lesion over the right trapezius incision. Despite treatment, this eroded to expose the shunt tube. On I3 May 1975 a portion of the shunt system was removed to prevent central nervous system infection. A subarachnoid cyst shunt was left intact. Patient has continued to improve with increased transfer power and increased finger muscles. Sensation has improved to C8 level bilaterally.

Case No. 7. M. D., 35-year-old female criminologist born with lumbosacral myelomeningocele and arrested hydrocephalus. Above-average intelligence. Paraplegia with recurrent renal-bladder problems. Three episodes since 1968 of recurrent right peripheral facial palsy. Last two years has had weakness right arm, blurred vision and neck pain. Neurologic examination revealed irregular lumbosacral myelomeningocele 4-5 $\mathrm{cm}$ in size. Flaccid paraplegia with sensory anesthesia to $\mathrm{L}_{4} . \mathrm{C}_{2}$ through $\mathrm{C}_{7}$ thermanesthesia are on the right with areflexia in right arm-Brevicollis. Computer axial tomogram showed hydrocephalus. Skull X-rays showed small posterior fossa and cervical spine X-rays showed Klippel-Feil syndrome. On 23 April 1975 angiography showed atrophic posterior fossa with ectopic cerebellar tonsils. On 28 April 1975 myelogram showed arachnoiditis of thoracic spine and ectopic cerebellar tonsils to $\mathrm{C}_{2}$ level. On 2 May 1975 suboccipital craniectomy was performed. Arnold-Chiari malformation and arteriovenous malformation upper cervical cord $\left(\mathrm{C}_{4}\right)$ was found. Cerebral spinal fluid leak developed postoperatively and on 30 May 1975 a right ventriculoperitoneal shunt was carried out. Postoperative recovery was uneventful with relief of blurred vision, headaches and increased strength and sensation of right arm.

Case No. 8. E. G., 6I-year-old female. I960 progressive paraparesis. I96I thoracic myelogram showed block D9. Thoracic laminectomy (I96I) and total resection D9 meningioma. Neurologic status returned to normal. Then over next two years progressive paraparesis. I963 second thoracic laminectomy at higher level revealed spinal cord cyst extending at least to D5. Rubber tube inserted. Postoperatively patient worse neurologically. Improved slightly but since 1969-70 progressive increase spasticity and ascending sensory loss. Neurologic examination revealed incomplete motor deficit in lowers with areflexia but positive Babinski. Marked thermanesthesia and analgesia to DI-2 with R. Horner's syndrome. Thoracic myelogram on 4 June 1975 showed block at D9-Io. Intramedullary myelography on same day showed cord cyst D9-Io to C7. Thoracic myelocyst-peritoneal shunt on 6 June 1975. Rapid drop of sensory level to D8 and decrease spasticity.

\section{Discussion}

Eight cases of cyst of the spinal cord have been presented. Two were congenital in type and six were post-traumatic in origin. All patients were operated upon by insertion of a silastic drainage tube into the cyst. In two cases the tube drained to the subarachnoid space, on one case a ventriculo-peritoneal shunt was performed, and in five cases a new procedure, myelocyst-peritoneal shunt, was carried out. All patients had immediate slight to significant neurological improvement and cessation of neurological deterioration. No patient was neurologically worse as a result of the operative procedure. Two shunt revisions were carried out, one to correct faulty tubing and the other to prevent central nervous system infection. No detrimental effects resulted from these revisions. 
Most authors who published surgical series concluded that surgery was beneficial in that, usually, there was cessation of neurological deterioration and, frequently, immediate objective and/or subjective neurological improvement. A significant problem with past operative approaches has been the recurrence of symptoms due to cyst recurrence secondary to myelotomy closure or tube malfunction. The recurrence of symptoms due to reaccumulation of cyst fluid has been greatest if percutaneous or operative needle aspiration, simple decompressive laminectomy or myelotomy have been utilised as the surgical method. It is, however, not unusual to have cyst-subarachnoid shunts using polyethylene, silk suture or tantalum wire fail to remain open. Thus, although unquestionably compared to medical or X-ray therapy, surgical therapy is the most rewarding treatment of spinal cord cysts, the particular method of surgery certainly needs considerable improvement.

The myelocyst-peritoneal shunt described in this paper has the potential of providing that needed improvement. The multi-purpose valve of this shunting method has several unique characteristics. The first feature is that there is a differential pressure valve within this mechanism which allows a variety of pressures to be obtained on both opening or closing. A low-pressure type valve No. 8500105 with an opening pressure of five centimetres of water and a closing pressure of three centimetres of water is used. This differential pressure aspect allows wide ranges of pressure variation, high val salva events or the normal low intracyst pressure to be handled without difficulty. At the same time that extreme pressures are managed the valve has the capability of handling in an intermittent fashion the lower pressure ranges to permit gradual drainage of the cyst. Another feature of the multi-purpose valve is the anti-siphon component which does not allow a reverse spinal movement of fluid when the pressure within the cyst or subarachnoid space becomes excessively low or lower than the intraperitoneal pressure. Perhaps, the most important feature of the multi-purpose valve is the on and off control mechanism which allows one to manually compress the on and off control transcutaneously and, subsequently, open or close the shunt system at will. Also transcutaneous needle-valve injection and aspiration of various materials such as radioactive isotopes, radio-opaque contrast agent, dyes, air and other substances can be performed on an out-patient basis. Thus, one can close the system and re-create the spinal cord cyst. Obviously an in vivo human experimental model now exists which may hopefully aid in determining the pathophysiology of these cysts. The clinical advantage is that for the first time the patency and function of a cyst shunt can be easily determined by the surgeon or patient.

The follow-up period of these cases ranged from a maximum of 12 months to a minimum of seven weeks. Due to this very brief follow-up period, to the small number of cases, and due to the well-known tendency of spinal cord cysts to exhibit natural remission of symptoms, the author emphasises that he cannot adequately evaluate the results of treatment in this series or the efficacy of the myelocyst-peritoneal shunt. Therefore, only in a theoretical manner will the potential advantages and disadvantages of the myelocyst-peritoneal shunt as compared to prior surgical methods be discussed.

The potential advantages of the myelocyst-peritoneal shunt are numerous.

(I) The laminectomy is limited (one laminal arch) and is performed in a virginal area of the spinal cord away from scar tissue. These factors decrease the neurologic risk, time of operation, and technical difficulty.

(2) The insertion of the cyst tube through a needle hole in the posterior median raphe is less damaging than incisional myelotomy. 
(3) Blockage of the shunt tube is less than closure of myelotomy.

(4) Transection of the spinal cord, a hideous procedure, is never carried out whether the patient's neurologic deficit is complete or incomplete.

(5) The function and patency of the system can be checked at any time by the patient or physician utilising a digital manipulation.

(6) Blockage of the shunt can be determined at any time by manual manipulation.

(7) If blockage is present, the site of block, spinal-peritoneal, may be determined by manual inspection. If the reservoir is distended and cannot be compressed the block is at the peritoneal end. If the reservoir is collapsed and will not fill, the block is at the spinal cyst end.

(8) This shunt system may be carried out in congenital communicating syringomyelia as well as other types of syringomyelia. This is less hazardous than suboccipital craniectomy and exploration of the fourth ventricle.

(9) Closure of the valve system can be accomplished at any time manually, creating an isolated spinal cord cyst when the valve is closed. Visually a 'dimple' occurs on the skin and can be easily observed. The open or closed nature of the valve may be proven with oblique X-rays, but this is not necessary with the above 'dimple' effect. Thus, experimentally one can inject various biological, radiological substances and further investigate the pathophysiology of spinal cord cysts.

(Io) Chemotherapeutic treatment of spinal cord neoplasms associated with spinal cysts could be accomplished with this method.

The disadvantages consist of infection associated with a foreign body implant and mechanical failure of the tube or valve system. Only further experience will determine the role of myelocyst-peritoneal shunts.

Other very interesting aspects of this investigation will be reported upon in other papers. The area regarding intramedullary myelography and its complications is pertinent. Clinical studies of spinal cord cysts in an effort to define pathophysiology are in progress. Comparative time studies of radioactive isotope activity in cyst fluid, subarachnoid fluid and blood are in progress. The possibility that intracyst fluid is created by extracellular transmyel fluid migration from the subarachnoid spaces is entertained by this author and that possibility is under investigation.

Finally, this procedure is technically undergoing continual change. Further modification of the cyst tube is in progress. Therefore, at the present time this is truly an experimental procedure, the fate of which will be defined by many future factors and individuals.

\section{SUMMARY}

A new surgical method, myelocyst-peritoneal shunt, has been performed on a small series of patients with congenital and acquired spinal cord cysts. In all cases, the progressive deterioration of neurological function ceased and all patients had slight to significant objective and/or subjective improvement in neurological function. The technical method is described along with individual case reports. Due to the short length of follow-up, the small number of operations, and the tendency for spinal cord cysts to spontaneously improve, the author discussed only potential advantages and disadvantages of this procedure as compared to 
prior spinal cord cyst operations. The creation of an in vivo human module spinal cord cyst by means of this operation has made it possible for the author to perform more basic ongoing investigation into the pathophysiology of spinal cord cysts and other similar disorders.

\section{RÉSUMÉ}

Une nouvelle méthode chirurgicale, la dérivation myélocysto-péritonéale, a été appliquée à une petite série de sujets atteints de kystes congénitaux et acquis de la moelle épinière. Dans tous les cas, la dégradation progressive de la fonction neurologique a cessé et tous les malades ont accusé une amélioration légère à importante, objective et/ou subjective de la fonction neurologique. La technique est décrite et des rapports de cas individuels l'accompagnent. Etant donné la courte durée du suivi, le petit nombre d'opérations réalisées, et la tendance qu'ont les kystes de la moelle épinière à s'améliorer spontanément, l'auteur se borne à discuter des avantages et inconvénients potentiels de cette méthode par rapport aux opérations antérieures des kystes de la moelle épinière. La création, au moyen de cette opération, d'un kyste de la moelle épinière "in vivo" sur module humain, a permis à l'auteur d'effectuer des recherches plus approfondies et continues dans le domaine de la pathophysiologie des kystes de la moelle épinière et autres affections analogues.

\section{ZUSAMMENFASSUNG}

Eine neue chirurgische Methode-Myelocyst-peritoneal shunt-wurde an einer kleinen Zahl von Patienten mit kongenitaler oder erworbener Rückenmarkszyste ausgeführt. In allen Fällen wurde die progressive Verschlinmerung der neurologischen Funktion aufgehalten und eine leichte objektive und subjektive funtionelle Besserung gefunden. Bei der kurzen Zeit der Nachbeobachtung diskutiert der Autor nur die potentiellen Vor- und Nachteile der Methode.

\section{REFERENCES}

Abbe, R. \& Coley, W. B. (I892). F. Nervous and Mental Diseases, 19, 5 I2.

Barnett, H. J. M., Foster, J. B. \& Hudgson, P. (I973). Syringomyelia, I, I60.

ConWAY, L. W. (1967). F. Neurosurg. 27, 501.

ElsBerg, C. A. (1916). Diagnosis and Treatment of Surgical Diseases of the Spinal Cord and its Membranes, 289. Philadelphia.

Gardner, W. J., Abdullah, A. F. \& McCormack, L. J. (1957). F. Neurosurg. 14, 59 I.

GARDNER, W. J. \& ANGEL, J. (1959). Clin. Neurosurg. 6, I3I.

Love, J. G. \& Olafson, R. A. (I966). F. Neurosurg. 24, 7I4.

Poussepp, L. (I926). Rev. Neurol. I, I I 7I.

Worster-Drought, C., Wakeley, Cecil P. G. \& Shafar, J. (194I). Brit. F. Surg. 29, 56. 


\section{Discussion}

Dr J. Grant (Australia). I should like to ask Dr. Edgar-I think most neurosurgeons are fairly intrepid-have you been worried about direct percutaneous puncture of the cysts? Has there been any deterioration in the neurological picture after you've filled the spinal cord cyst up with lipiodol? Thirdly, do you take it out afterwards?

Dr EDGAR (U.S.A.). First of all, we are very concerned, I wish that there was a way we could get around percutaneous puncture. We have had complications from intramedullary myelography, three of them, which will be reported, in two cases there was a transient seven-day weakness of the right wrist extensor, which I felt occurred at the time of introduction of the needle into the spinal cord. These recovered completely. The third complication was a profound, sustained autonomic dysreflexia in the patient who had a cyst extending from $\mathrm{CI}_{\mathrm{I}}$ to LI. This was finally controlled. We do remove the contrast fluid as completely as possible and we are now obtaining permission in the United States at our hospital for use of water-soluble contrast agents. Obviously, the use of radioactive isotopes is a preferable method, although it does not eliminate the dangers of intramedullary myelography but it does, I think, potentially result in less scarring. 